\title{
Adding insult to rivalry: Exploring the discord communicated between rivals
}

Jennifer L. Harker

West Virginia University, jennifer.harker@mail.wvu.edu

Jonathan A. Jensen

UNC-CH, jajensen@email.unc.edu

Follow this and additional works at: https://researchrepository.wvu.edu/faculty_publications

Part of the Interpersonal and Small Group Communication Commons, Public Relations and Advertising Commons, Social Psychology Commons, Sports Management Commons, and the Sports Studies Commons

\section{Digital Commons Citation}

Harker, Jennifer L. and Jensen, Jonathan A., "Adding insult to rivalry: Exploring the discord communicated between rivals" (2020). Faculty \& Staff Scholarship. 2848.

https://researchrepository.wvu.edu/faculty_publications/2848

This Article is brought to you for free and open access by The Research Repository @ WVU. It has been accepted for inclusion in Faculty \& Staff Scholarship by an authorized administrator of The Research Repository @ WVU. For more information, please contact ian.harmon@mail.wvu.edu. 


\title{
Adding insult to rivalry: Exploring the discord communicated between rivals
}

\author{
Jennifer L. Harker \\ Reed College of Media, West Virginia University, Morgantown, West Virginia, \\ USA, and \\ Jonathan A. Jensen \\ University of North Carolina at Chapel Hill, Chapel Hill, North Carolina, USA
}

\begin{abstract}
Purpose - The purpose of this research is to extend current knowledge regarding rivalry communication among sport consumers to better understand how rivals behave with one another when they communicate.

Design/methodology/approach - This national survey of US sport consumers used a novel approach to explore whether and with whom rivals discuss National Football League (NFL) game outcomes. The survey captured both uniplex and multiplex data by asking respondents to name rival discussants with whom they had recently interacted, and the fan behaviors they exchanged with those named rival discussants.

Findings - Through use of this novel data collection approach, new findings were uncovered related to blasting, glory out of reflective failure, schadenfreude and the influence of team identification on the exchange of rivalry fan behaviors. The results of the uniplex and multiplex data analyses uniquely showcase the ways in which social identity theory combines with team identification to enact rivalry behavior.

Originality/value - This research is the first to precisely dichotomize the psychological antecedents from the communicated behavior between rival fans. Results reveal the precise ways in which team identification influences discordant communication between rival fans, which differs from past research in an interesting new way.
\end{abstract}

Keywords Rivalry, Fan behavior, Team identification, GORFing, Schadenfreude, Blasting

Paper type Research paper

Researchers have long studied the dramatization of sport fans. From painted, unclothed bodies in subzero temperatures to hooliganism, sport fans are among the most unpredictable humans researched within the social sciences. Over the past 40 years, researchers in the fields of social psychology, sport communication and sport marketing have developed and explored a body of research regarding fan behavior. Fan behavior studies have ranged from observations and experiments to surveys of psychological antecedents to behavioral outcomes. Common themes and consensus throughout this body of research include the psychosocial areas of social identity, image management and social comparison.

The transfer of competition from field to a fan's everyday life is due to the identification a fan establishes with his or her favorite team. Team identification subsequently connects a person with other members of an in-group (Wann, 2006). For example, a fan's team identity includes identification with other fans of that team, and that group identity expands into social comparison with other teams, or rivals. In other words, rival teams and fans become part of a sports fan's team identity (Billings et al., 2017). Wann (2006) notes that such social connections built with other fans can be positive or negative. Sport fans are likely to enjoy positive relationships with like-fans due to their common interest in a particular team. Rivals, however, share a strained relationship due to the identity threat felt by highly identified fans. Overt emotional responses can occur when one team or the other wins when competing against each other. Rivalry extends in other ways, too. Sometimes, a fan's actions are overt, spontaneous and expressed as an out-group derogation (Cialdini and Richardson, 1980;

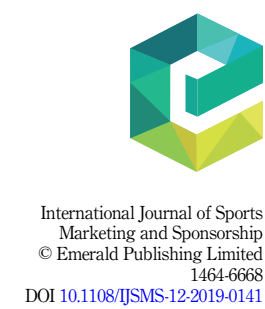


Converse and Reinhard, 2016; Spinda, 2011). Rivals will "blast" each other by talking trash and putting down the rival or minimizing the rival team's win, as a form of out-group derogation (Cialdini and Richardson, 1980).

Glory out of reflective failure, or GORFing, is an extension of rivalry reactions to game outcomes (Havard, 2014). GORFing is a socialization and in-group bias that leads to feelings of satisfaction when a rival team loses a game. This feeling of joy at another's adversity is termed schadenfreude (Heider, 1958; Tyler et al., 2019). These two complex feelings among fans concerning rival counterparts seem intuitive, yet are emerging and understudied concepts in the sport communication and sport marketing literatures (Billings et al., 2017; Havard, 2014). GORFing and schadenfreude are operationalized in the current research as social and affective antecedents to the expressed derogatory communication exchanged between rivals. Schadenfreude is a felt emotion (joy) in response to a rivalry competition in which one's favorite team wins.

This research builds upon the fan behavior literature by dichotomizing the socialpsychological antecedents (i.e. schadenfreude as affect) that trigger behavior (i.e. blasting). The study explores rivalry communication among fans of National Football League (NFL) teams by asking respondents to specifically name their rival discussants, then respond to fan behavior questions regarding shared exchanges with each named rival discussant. This novel approach to rival communication extends prior rivalry and fan behavior studies through use of multiplex relational data involving personal, specifically named rival discussants. This research is therefore able to unearth meaningful insights that reveal detailed explanations concerning rivalry fan behavior. The next section discusses the sport marketing and fan behavior literature, while positioning the current investigation within team identification, to discuss the affective and behavioral propensities of sports fans.

\section{Literature review}

The collective body of fan behavior literature has grown over the past 40 years. Studies note that emotional responses are more pronounced among sport consumers (Gantz et al., 2006; Reysen and Branscombe, 2010), and an array of studies have connected social identification and fan behavior to these emotional responses (Billings et al., 2017; Spinda, 2011; Wann and Branscombe, 1993). Researchers are now exploring the underlying personality traits that drive fan behaviors (Brown-Devlin et al., 2017). At the root of these behaviors are: image management, in-group/out-group bias, social comparison, superiority and identity threat (Cialdini et al., 1976; Cialdini and Richardson, 1980; Tajfel and Turner, 1986, 1979; Wann, 2006). This section surveys these affectively driven sport consumer behaviors.

\section{Team identification and social identity}

An individual can feel a psychological connection to a particular sport or team (Kruse, 1977, 1981; Wann et al., 2001). This perceived connection is often termed team identification (Wann and Branscombe, 1993). Team identification is a measurement of being a fan of a team and is defined as how much an individual enjoys, holds interest in and identifies with that team (Reysen and Branscombe, 2010). For some, that identifying connection can grow stronger than for others and can range from a casual connection to a "primary social identity" (Hirt and Clarkson, 2011, p. 3).

Individuals work toward a positive social identity in an effort to avoid a perceived negative social identity (Heider, 1958; Tajfel and Turner, 1979; Weiner, 2008, 1986). This means people will connect with or distance themselves from what is perceived as favorable ingroup and comparative out-groups, respectively. According to social identity theory, this process begins at the individual level and grows outwardly (Tajfel and Turner, 1979), 
therefore an individual's identifiable social groups or self-categorizations grow and overlap over the course of one's life.

When a social in-group identity is challenged in any negative manner-such as a losing season in sport - efforts are taken to "differentiate" oneself or one's group (Tajfel and Turner, 1979, p. 40). This differentiation might occur by either leaving the in-group or reshaping the in-group to be more positively viewed than a comparative out-group (Tajfel, 1982). As such dissonance occurs, the individual works to close that cognitive gap by highlighting the positive attributes of the in-group or by highlighting the negative attributes of the out-group (Tajfel and Turner, 1979). To translate this concept to sport, a football fan might minimize a loss to a rival team with accusations that the rival team cheated or that the referees were onesided that day. Highly identified fans engage in a kaleidoscope of psycho-social coping strategies in response to game outcomes, which can range from positive to negative and psychological to overtly behavioral (Wann, 2006).

Four characteristics of social identification are sensibly applicable to sport. The characteristics include (Tajfel and Turner, 1979): internalization of belonging (e.g. Green Bay fans are "Cheeseheads"); group comparisons focused on certain attributes (e.g. how many championships have been won by favorite team versus a rival team); out-group comparisons with a worthy opponent (e.g. playing last year's Super Bowl winner) and superiority maintenance (e.g. we have the leading rusher in the league). The superiority characteristic arguably links to the triggering "identity threat" that comes along with the less favorable outcomes inherent to sport (Wann, 2006), but superiority is additionally a characteristic maintenance attempt that minimizes comparison (Tajfel and Turner, 1979, p. 39).

Social comparison is conceptualized as the act of relationally comparing one's own group to other out-groups (Tajfel and Turner, 1986). Rees et al. (2015) note that in sport specifically, social identity is both relational and comparative, which is the very basis of sport-related group behavior. Social comparison happens in all types of subgroups with which one might identify (Tajfel and Turner, 1986), but is particularly strong in sport (Rees et al., 2015). Social identification and social comparison strengthen as in-group distinctiveness grows and being part of a socially favorable group, like a winning team, offers superiority over other outgroups, rivals or losing teams (Mael and Ashforth, 1992; Ashforth and Mael 1989; Wann, 2006).

Personal and interpersonal involvement with sport both nurture and strain social interactions and relationships (Funk and James, 2001, p. 127). Sport is a social construct, but interactions can become strained when there is a perceived identity threat. Wann (2006) offers the best analogy of this: "Indeed, the nature of athletic competition guarantees that roughly half of the fans will be disappointed in the outcome" of a game (p. 277). It is here that identified sport fans engage in image management.

\section{Fan behaviors}

The body of research on sport fan behaviors emerged in the 1970s with "basking in reflective glory" or BIRGing (Campbell et al., 2004; Cialdini et al., 1976; Cialdini and Richardson, 1980; End et al., 2002; Jensen et al., 2016; Sigelman, 1986; Spinda, 2011; Wann and Branscombe, 1990). BIRGing was first observed as a demonstrated image management strategy when researchers observed students wearing university logoed apparel on the Mondays following a Saturday game day win (Cialdini et al., 1976). Such display of "vicarious achievement" (Campbell et al., 2004, p. 151) highlights how team identification strengthens through social identification and how superiority is celebrated when an image threat (Wann, 2006) is overcome. This "celebrating our achievements together" or COATing relates to fans using descriptors such as "we" and "us" when talking about or reminiscing about a team's win (Cialdini et al., 1976; Jensen et al., 2016). Fans of losing teams also attempt to maintain a
Adding insult to rivalry 
positive identity by "cutting off reflected failure" or CORFing (Campbell et al., 2004; DietzUhler and Murrell, 1999; Jensen et al., 2016; Spinda, 2011; Wann, 2006; Wann; Branscombe, 1990). Fans of such teams may also choose to remain affiliated with losing teams, as they view their continued association with as loser as a badge of honor, by "basking in spite of reflected failure," or BIRFing (Campbell et al., 2004; Jensen et al., 2018).

\section{Rivalry fan behaviors}

Rivalry fan behaviors include direct and indirect communicated acts and affective perceptions. "Blasting," for example, can be an indirect or direct derogative communicated act. Blasting is prevalent among highly identified fans and is generally exchanged with or about rivals. "Glory out of reflected failure" and "schadenfreude" are two affective relational rivalry outcomes discussed in more recent fan behavior studies. This section provides an overview of these rivalry fan behaviors and explores how each relates to sport fans' behaviors following game outcomes.

Blasting. Cialdini and Richardson (1980) experimented with student reactions to negative and positive in-group perceptions, finding that students applied image management in speaking positively of their own university and speaking negatively about a rival university. This out-group derogation was originally coined an indirect image management strategy. Later, blasting was applied to sport and operationalized to include explicit negative acts of communication (Bernache-Assollant et al., 2007; Havard, 2014; Spinda, 2011). However, this leap did not include a full discussion as to whether the newer operationalization still reflected image management or perhaps something new. For instance, blasting was noted as more "contextual than universal" (Bernache-Assollant et al., 2007, p. 386) and is more a matter of a strong positive connection to a team's in-group and less about the fan's need to derogate the out-group, or rival team's fans, because doing so would "grant them too much importance" (Bernache-Assollant et al., 2007, p. 386; Wann and Dolan, 1994). Blasting has since fully evolved into a direct communicated act defined and operationalized as "talking trash" (Spinda, 2011).

GORFing. Glory out of reflected failure is a form of gloating, yet less overt (Havard, 2014). GORFing is measured by asking fans about their feelings following a loss by their rival team to their favorite team or to any other team. The four major themes that have emerged to form this GORFing concept include: socialization, in-group bias, a sense of satisfaction and outgroup indirect competition. The fans interviewed varied in their perceptions of rivalry wins and losses. Some wished the rival team no ill-will and would be pleased with the rival team winning any game outside of the match with their own favorite team. Some wished rivals lost every game, but mostly the respondents gauged such feelings on what the rival team's record would mean for their own team's success for the season.

GORFing was later extended quantitatively by examining four affective measurements that include happiness, satisfaction, relief and pride (Billings et al., 2017). GORFing in this latter study reflects the individualized feelings a fan holds when a rival team loses to a favorite team or to any other of the favorite team's rivals. Those four affective measurements applied as GORFing are the underlying facets of schadenfreude, which is a feeling of joy at another's adversity (Heider, 1958). Schadenfreude, warned Heider (1958), is harmful to social relationships because it is discordant to harmonic relationships.

Schadenfreude creates an antagonistic relationship, similar to the other fan behaviors demonstrated between rival sport fans (Havard, 2014; Leach et al., 2003). The study of schadenfreude has taken shape by studying its presence in business and then in sport (Cikara et al., 2011; Cikara and Fiske, 2012; Leach et al., 2015; Leach et al., 2003; Leach and Spears, 2009; Heider, 1958). Schadenfreude is conceived in three ways: when a misfortune befalls an envied person, misfortune is perceived as deserved and when something might be gained for 
the observer from that misfortune (Cikara and Fiske, 2012). For example, Leach and Spears (2009) measured the appearance of business professionals and told participants in an experiment differing stories about the individuals. Respondents were most likely to report feeling joyful in response to a successful businessman's troubled scenario than to other people's scenarios. Finding joy in another's adversity brings into question the role of envy. The study's findings suggest envy is a predictor of schadenfreude, but that other affective measurements are also linked. For instance, schadenfreude-related emotions include joy, happiness, relief, satisfaction, pride, gloating, sympathy and sadness (Leach et al., 2003, 2015; Leach and Spears, 2009).

Schadenfreude in response to sport stems from an in-group envy toward a winning rival team or a team of perceivably higher status (Cikara and Fiske, 2012; Leach et al., 2015) and correlates with higher levels of team identification (Leach et al., 2003). In fact, the psychological connection of schadenfreude and sport has been backed by neurological science. Cikara et al. (2011) observed baseball fans with MRI brain scans as they watched plays and game outcomes of their favorite and rival baseball teams. Results resoundingly showed that sport fans activated the area of the brain that signifies happiness when his/her team played well or won a game. More interestingly, fans demonstrated even higher levels of happiness when a rival team lost or played poorly. The researchers additionally noted that the anger and pain areas of the brain were activated when a fan's favorite team lost and when a rival team won.

Rivalry fan behaviors span from envy-driven joy at another's adversity to direct and indirect derogatory communication. Identification, socialization, superiority and perceived identity threats are among the psychosocial undercurrents of these affective and behavioral reactions to rivalry game outcomes. The next section explains how the current research extends current knowledge regarding rivalry ban behavior.

\section{Research hypotheses}

The current study responds to a call to quantitatively examine the differences between GORFing and schadenfreude (Havard and Dalakas, 2017, p. 201). Sport rivalry is defined as "a fluctuating adversarial relationship" between "groups of fans" that "gains significance" through competition (Havard et al., 2013, p. 51). Rivalry is rooted in a storied history of one's favorite team (Converse and Reinhard, 2016), is an identity threat (Berendt and Uhrich, 2016) and becomes a part of a fan's identity (Billings et al., 2017). Recent research identified three primary dimensions of rivalry: (1) conflict, (2) peer and (3) bias (Tyler and Cobbs, 2015) and the current research reflects these three dimensions by examining the conflict communicated between peers and the bias that drives such conflict between (rival) peers. The current study therefore explores the derogatory communication exchanged between rival fans of NFL teams because NFL fans harbor and express significant animosity toward their perceived rivals, even more so than fans of other professional leagues (Cobbs et al., 2017).

Team identification and fan behaviors are regularly reported as associated with rivalry (Berendt and Uhrich, 2016; Billings et al., 2017; Branscombe and Wann, 1994; Spinda, 2011; Wann and Branscombe, 1993, 1990). The current study anticipates team identification to remain associated with rivalry fan behavior and therefore hypothesizes that team identification will be a significant predictor of directly communicated rivalry fan behavior. Therefore:

H1. Team identification is a predictor of the blasting rivalry fan behavior.

One missing aspect in rivalry fan behavior research is the quantitative measurement of respondents' perceptions of their rival discussants' level of fanship. For example, will superiority or social comparison leave a fan thinking they are more of a fan of their team than 
their rival team's fans? As Berendt and Uhrich, (2016) noted, rivalry can also be an identity threat, so will a perceived threat increase or decrease a fan's identity as a predictive variable for engaging in discordant communication?

The current study investigated this research question by collecting data related to respondents' perceptions of their rival discussants' fanship, in addition to the communicated behaviors they exchange with one another. Team identification is commonly only assessed as the respondent's level or strength of team identification. This study, however, additionally captures respondents' perceived rival discussants' level of fanship. This measurement was captured given that socialization, social comparison, image management and image threats have all been conceptualized within sport rivalry. Therefore, the following research question is explored:

$R Q 1$. What role will the perceived fanship of named rival discussants play in the activation of rivalry fan behaviors?

Shifting now to the demonstrated fan behaviors exchanged between rivals, Billings et al. (2017) packaged the four affective measurements related to schadenfreude and operationalized them as a GORFing scale. This study unpacks these affective antecedents and explores which specific components of schadenfreude are directly related to expressed derogation between rivals. As such, the following final research question is presented:

$R Q 2$. Which GORFing and schadenfreude components are predictive of the direct expression of derogatory communication between rival discussants?

The next section is a review of the method utilized to examine these research questions and answer the hypothesis regarding communicated fan behaviors between rival discussants. The unique data collection process is explained and all measures are detailed.

\section{Method}

An online survey was conducted with American adults who self-identified as having a favorite NFL team. This national survey was launched during the 2017-2018 football season, and data were collected for several consecutive weeks on different days and at differing times of day. Qualtrics data collection services were used, which offers protections against data abuses such as speeders, straightliners or respondents who fall outside of contingent inclusionary demographics set by researchers. One screening question, "Are you a fan of sports?" was asked and only "yes" responses were allowed to participate in the survey. Qualtrics handled all incentives by offering reward points.

The key variables were captured for this study by using personal landmark aids (van der Vaart and Glasner, 2011). To explain, respondents were asked to recall specific and functional discussants within a specified timeframe. Jarring a memory model in such a manner increases recall elements such as the feelings or perceptions or other cognitive processes. Such a process in survey administration aids in recall specification. To better explain the resultant data from this process, variables are discussed hereunto as uniplex and multiplex. Uniplex variables refer to respondent-only information, such as respondent demographics and respondent perceptions. The multiplex variables include those that represent memory model activation of perceptions and behaviors exchanged with named rival discussants. Respondent measures included demographics (age and gender), favorite NFL team, a team identification scale (Wann and Branscombe, 1993) and likelihood to blast following a win or a loss by the respondent's favorite team.

Rival discussants are operationalized in the current study as individuals within a respondent's online and offline social network who are fans of teams that are rivals to the respondent's favorite team and with whom respondents discuss game outcomes. Rival 
discussants were collected by asking the survey respondents to list up to five individuals who are fans of rival teams to their own favorite NFL team with whom they have discussed sports within the past month. The number of discussants that respondents list can vary, but it was important to allow variety in rival identification because fans perceive multiple rivals of their favorite team (Tyler and Cobbs, 2017). Researchers request between 5 and 10 names during this type of survey process, much like scale points in other scientifically rooted measurements, but the average number of named discussants typically rests at three (Bush et al., 2017; Marsden, 1987; Perry and Pescosolido, 2015, 2010). Rival discussants were captured by asking respondents: Can you list anyone you have spoken to in the past month about sports who is a fan of a RIVAL team to [respondents' named favorite NFL team]? And because we specifically were interested in rivalry communication, we asked, "please write the names of people who come to you to talk about sports, whether you want them to or not."

The remainder of items were all measured utilizing a seven-point Likert-type scale. The remaining measurements include those exchanged between rival fans. Rival interactions and intensity vary between rivals, so all questions related to communication exchanges between respondents and their named rival discussants were asked along the seven-point Likert-type continuous scale (Tyler and Cobbs, 2017).

In-group bias was measured as respondents' team identification. Team identification has been consistently regarded as a predictor of fan behaviors. The sport spectator identification scale (SSIS) is a reliable fan-measurement scale widely applied in sport consumer behavior research (Wann and Branscombe, 1993). The seven-item scale was adapted for this study by asking respondents to first identify their favorite NFL team and then the name of that team was piped into each SSIS question. For example, "How important is it to you that [favorite NFL team] wins?" The team identification scale achieved internal consistency with respondents reporting a moderate level of identification with favorite NFL team $(a=0.93$; $n=936, M=4.89, S D=1.58$ ).

A single question sport fan measure was additionally captured (End et al., 2002). Respondents rated themselves on how much they perceive themselves to be a sport fan. Results for the one-question sport fan measurement had a slightly higher mean than the team identification scale $(n=1,018, M=5.05, S D=1.89)$. Only the team identification scale was used in subsequent inferential statistics related to team identification of the survey respondents. The single question sport fan rating was also asked regarding each rival discussant to capture the respondents' perceptions of their rival discussants' fanship. The measure was captured for each rival discussant the respondent listed. The respondent was asked: "Please indicate how much you perceive each person as not at all a fan of sports (1) to very much a sports fan (7)." Results $(n=313, M=5.36, S D=1.73)$ suggest respondents view their rival discussants as more highly identified fans than themselves.

Rivalry was captured as the respondent naming a discussant for the specific and functional purpose of being one's rival, as such the sport rivalry fan perception scale was not appropriate for this study (Havard et al., 2013). The concept of socialization was extended in the current study from Havard's (2014) original conceptualization and additionally operationalized as relational exchanges between respondents and their named rivals. The relational exchanges included watching, attending and talking about sports together. Respondents were asked to report how often they engaged in each relational exchange with each rival they had listed: "How often do you WATCH sporting events together?" $(n=308$, $M=2.77, S D=1.98)$, ATTEND $(n=306, M=2.38, \mathrm{SD}=2.00)$, and TALK about $(n=305$, $M=3.67, S D=1.99$ ).

Havard (2014) explained sense of satisfaction as the excitement or pleasure derived when a rival team loses a game. The current study operationalizes sense of satisfaction as three schadenfreude-related measurements that are directly communicated with rival discussants: joy, pride and insult. Pride was used instead of "bragging rights" from the sport rivalry fan 
perception scale (Havard et al., 2013). Insult was added to this investigation as an expression of exchanged animosity (Cobbs et al., 2017). Respondents were asked, "How likely are you to communicate feelings of joy to each person if his/her favorite team loses a game?" "How likely are you to communicate feelings of pride to each person if his/her favorite team loses a game?" and "How likely are you to personally insult each person if his/her favorite team loses a game?" It is important to note here that insult was measured separate and distinct from "talking trash" when blasting.

Contrary to past research, this study measures both direct and indirect competition, and the likelihood to blast as a result of either, by asking respondents: "If a RIVAL team loses to [favorite NFL team] how likely are you to trash talk to a fan of that rival team?" $(n=936$, $M=3.42, S D=2.18$ ); and "If a RIVAL team loses to any other NFL team, how likely are you to "trash talk" to a fan of that rival team?" ( $n=935, M=3.13, S D=2.12)$.

Blasting is measured as an identification-driven out-group derogation communicated between rival discussants following game wins and losses. Respondents were asked, "How likely are you to 'trash talk' to each person listed following a WIN/LOSS by [your favorite NFL team]?” (Spinda, 2011).

\section{Results}

Respondents $(N=1,029)$ of the survey reported an average age of 45.7 years $(S D=16.88$ years) with a near-even split among gender: $56.7 \%$ male $(n=583)$ and $43.3 \%$ female $(n=446)$. See Table 1 for a full list of all descriptive statistics. All subsequent measures were analyzed using what was explained above as multiplex variables, which were informed by each respondents' listed rival discussants. Recall here that respondents were asked the remaining questions regarding each rival discussant they listed. This strategy aids in collecting functionally specific data in social relationships (Perry and Pescosolido, 2010). Rival discussants $(n=313)$ were collected by asking respondents to list up to five individuals with whom they have discussed sports who are fan of a rival team to their own favorite NFL

\begin{tabular}{lrccc}
\hline$N=1,029$ & $N$ & $M$ & SD & Missing $\mid \%$ \\
\hline Age & 989 & 45.7 & 16.88 & 40 \\
Gender (dummy coded: 1 = male) & 1,029 & 0.57 & 0.50 & 0 \\
Male & 583 & & & $56.7 \%$ \\
Female & 446 & & & $43.3 \%$ \\
Team identification & 936 & 4.89 & 1.58 & 93 \\
Blast after a win & 936 & 3.30 & 2.16 & 93 \\
Blast after a loss & 936 & 2.91 & 2.01 & 93 \\
Likelihood to blast rival: fav team & 936 & 3.42 & 2.18 & 93 \\
Likelihood to blast rival: any team & 935 & 3.13 & 2.12 & 94 \\
Rival discussant is a sports fan & 313 & 5.36 & 1.73 & 716 \\
Schadenfreude: communicate joy & 311 & 3.48 & 2.23 & 718 \\
Schadenfreude: communicate pride & 310 & 3.38 & 2.21 & 719 \\
Schadenfreude: personally insult & 312 & 2.42 & 2.08 & 717 \\
Watch sports together & 308 & 2.77 & 1.98 & 721 \\
Attend sporting events together & 306 & 2.38 & 2.00 & 723 \\
Talk about sports together & 305 & 3.67 & 1.99 & 724 \\
Dependent variables & & & & \\
Blast 1: respondent blasts rival & 306 & 3.51 & 2.26 & 723 \\
Blast 2: rival blasts respondent & 311 & 3.68 & 2.26 & 718 \\
Note(s): all measures were captured along a seven-point scale, increasing in intensity & \\
& & & &
\end{tabular}

Table 1.
Descriptive statistics of key variables

Note(s): all measures were captured along a seven-point scale, increasing in intensity 
team. The data reported here were collected as part of a larger study (Harker, 2018), using a uniquely created, sport-focused instrument informed by a former PhenX Toolkit (1991) instrument that has been used for decades of investigation into interpersonal, health and political communication. It is important to note here that the 1,029 survey respondents named only 313 rival discussants, which speaks to the disidentification component related to sport rivalry. In other words, sport rivalry scholars might argue that rivals make a conscious effort to avoid communication exchanges with rivals; however, rivalry communication can never truly be avoided. The current research investigates these unavoidable exchanges that occur throughout a sports fan's online and offline social network. Once the rival discussants were listed, all subsequent questions were asked as perceptions or recall of actual behavior regarding each individual rival discussant. For example, respondent number 23 listed four rival discussants so the respondent was asked to answer each question four times - one answer per listed rival discussant. This process resulted in functionally specific multiplex variables relating back to each rival discussant. Descriptive statistics for each variable are reported in Table 1.

The current study intended to answer one hypothesis and two research questions regarding (1) the role of team identification in fan behaviors between rival discussants, and (2) which components of GORFing and Schadenfreude might be predictive of that communicated behavior between rival discussants. A series of regression analyses were conducted and the first two models are reported side-by-side in Table 2.

The first model $(F(10,250)=27.16, p<0.001)$ explained half $\left(R^{2}=51 \%\right)$ of the variance for blasting rival discussants following a win of respondents' favorite team $(M=3.51)$. Perception of the rival discussant's level of being sports fan was predictive $(\beta=0.121$, $p=0.018$ ) of blasting following a win of the respondents' favorite team. All three of the Schadenfreude components were predictive, which suggests fans feel joy $\beta=0.264$, $p<0.001)$ and pride $(\beta=0.178, p=0.044)$ and are likely to insult $(\beta=0.327, p<0.001)$ rival discussants after a win.

NFL fans also reported being blasted by rival discussants after a respondents' favorite team loses a game $(M=3.68)$. The model $(F(10,254)=24.29, p<0.001)$ explained nearly half $\left(R^{2}=48 \%\right)$ of the variance for being blasted. Respondents reported being blasted by rival discussants who they perceive to be highly identified fans $(\beta=0.163, p=0.002)$. Again, joy $(\beta=0.284, p=0.001)$ and insult $(\beta=0.305, p<0.001)$ are predictive factors.

\begin{tabular}{lcc}
\hline & Blast 1 & Blast 2 \\
\hline$n=$ & 251 & 255 \\
Age & -0.085 & -0.074 \\
Gender (male) & -0.07 & -0.047 \\
Team identification & 0.048 & 0.003 \\
Rival discussant is a sport fan & $0.121^{*}$ & $0.163^{* *}$ \\
Watch sports together & -0.01 & -0.001 \\
Attend sporting events together & -0.079 & -0.093 \\
Talk about sports together & 0.036 & 0.049 \\
Schadenfreude: joy & $0.264^{* * *}$ & $0.284^{* * *}$ \\
Schadenfreude: pride & $0.178^{*}$ & 0.15 \\
& & \\
Schadenfreude: insult & $0.327^{* * *}$ & $0.305^{* * *}$ \\
$R$ & 0.53 & 0.50 \\
$R^{2}$ & 0.51 & 0.48 \\
$F \mid$ Model significance* & $27.16^{* * *}$ & $24.29^{* * *}$
\end{tabular}

Note(s): ${ }^{*} p<0.05, * * p<0.01,{ }^{* * *} p<0.001$. Blast $1=$ respondent blasts rival after respondents' favorite team wins; Blast $2=$ rival blasts respondent after respondent's favorite team loses

Adding insult to rivalry

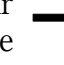

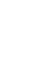


A second set of regression models were analyzed to test Havard's (2014) categorization of the indirect competition component of GORFing. The two models were built using those respondents who reported activation of outward blasting with named rival discussants. The two models were built by categorizing those who reported a likelihood to blast rival discussants who lose a game to the respondent's favorite team and those who reported a likelihood to blast after a rival team loses to any team. Both models are reported side-by-side in Table 3.

The first model testing the GORFing categorization explained half $\left(R^{2}=51 \%\right)$ of the variance for blasting named rival discussants when the rival discussant's team loses to the respondent's favorite team, $F(10,240)=24.92, p<0.001$. Younger $(\beta=-0.238, p<0.001)$, highly identified fans $(\beta=0.288, p=0.001)$ are expressing joy $(\beta=0.171, p=0.053)$ regarding their favorite team's win by insulting $(\beta=0.347, p<0.001)$ rival discussants.

The second model conducted to test the GORFing categorization explained nearly half $\left(R^{2}=47 \%\right.$ ) of the variance for blasting named rival discussants when the rival discussant's team loses to any team, $F(10,240)=21.10, p<0.001$. This model tests the indirect competition component of GORFing (Havard, 2014) and results suggest younger $(\beta=-0.146, p=0.015$ ), highly identified fans $(\beta=0.251, p=0.001)$, insult $(\beta=0.360, p<0.001)$ rival discussants regarding their team's loss.

The results of these two models suggest sense of satisfaction, or joy at another's adversity, is a predictive affective element when blasting a rival discussant whose team loses to the respondent's favorite team. However, in the indirect competition model, sense of satisfaction was nonsignificant. In both models, insulting rival discussants was again the strongest significant predictor of activating the blasting fan behavior. The socialization components beyond named rival discussants were all insignificant, as would be expected between rivals. Next is a discussion of these results, with a focus toward future research regarding whether GORFing and schadenfreude are distinguishable fan behavior perceptions.

\section{Discussion}

The current study examined the out-group derogation that is communicated between rival NFL fans. First, the exchange of blasting between NFL fans was analyzed. Then, an analysis of the predictive components for those who reported blasting their rival discussants was

Table 3.

Regression analyses for activation of outgroup derogation by game outcome

\begin{tabular}{lcc}
\hline & Favorite team & Any team \\
\hline$n=$ & 251 & 251 \\
Age & $-0.238^{* * * *}$ & $-0.146^{* * *}$ \\
Gender (male) & 0.074 & 0.042 \\
Team identification & $0.288^{* * * *}$ & $0.251^{* * *}$ \\
Rival discussant is a sport fan & -0.5 & -0.101 \\
Watch sports together & -0.003 & -0.049 \\
Attend sporting events together & -0.011 & 0.069 \\
Talk about sports together & 0.011 & 0.049 \\
Schadenfreude: joy & $0.171^{*}$ & 0.110 \\
Schadenfreude: pride & 0.004 & 0.064 \\
& & \\
Schadenfreude: insult & $0.347^{* * *}$ & $0.360^{* * * *}$ \\
$R$ & 0.71 & 0.68 \\
$R^{2}$ & 0.51 & 0.47 \\
$F \mid$ Model significance* & $24.92^{* * *}$ & $21.10^{* * * *}$
\end{tabular}

Note(s): ${ }^{*} p<0.05,{ }^{* *} p<0.01,{ }^{* * *} p<0.001$. ${ }^{*}$ Rival team loses to respondents' favorite team (direct rivalry) or rival team loses to any team (indirect rivalry) 
performed, in relation to whether a rival discussant's team loses a game to the respondents' favorite team or whether the rival discussant's team loses a game to any team. By collecting multiplex relational data involving personal, specifically named rival discussants, the current study was able to generate detailed explanations concerning the differences that exist in rivalry fan perceptions and rivalry fan behavior, even in relation to the categorizations of GORFing despite the fact that past research has noted no differences exist (Havard and Hutchinson, 2017). This research uniquely emphasizes the need to categorize the study of fan behaviors as more than simple behavior and include deeper discussions involving the affective and social antecedents to this discordant behavior. Such dichotomization, coupled with the multiplex relational variables and the personal landmark data collection process, aided in teasing out the activating components key to better understanding rivalry fan behavior.

In sum, the first hypothesis (H1) stated team identification is a predictor of directly communicated rivalry fan behavior. H1 was only partially supported in the current study, given that when the respondent answered recall questions regarding interpersonal communication exchanged with their own named rival discussants, the other person's perceived fanship gained significance. The hypothesis was however supported in the second set of models where team identification was significant, given that the respondent was surveyed about their general perceptions of their rivalry behavior and not the actualized behavior with a functionally specific rival discussant. H1 aided in answering RQ1, which asked what role perceived fanship of named rival discussants might play in the activation of rivalry fan behaviors. Results suggest that a fan's perception of their rival out-group is at least somewhat influential in activating fan behavior. Historically, we have been measuring these complex relational fan behaviors in a strictly uniplex manner, which has built knowledge and directed measurement to enable this deeper study into these phenomena. The current relational examination of the interpersonal activation of fan behaviors has now offered a new, more in-depth analysis reflective of the relational complexity inherent to social science.

Of note is that the respondents' level of team identification showed no significance in activating the outward blasting fan behavior, nor the reporting of being blasted by rival discussants. This result is counter to what past research has suggested, but is likely because of the personal landmark memory model recall data collection process, which requires respondents to answer survey questions related to their personal, tangible relationships and experiences (van der Vaart; Glasner, 2011). This process narrows social selection and activation of behavior for functional specificity (Perry and Pescosolido, 2010). In other words, respondents reach to certain others to fulfill specific and functional needs and when respondents activate that specific memory model, there is more variance within that recall than had the respondent answered in generality. These results also suggest that rivals who are perceived as highly identified fans are those with whom NFL fans wish to express schadenfreude and personally insult over positively perceived game outcomes. This is likely due to the image threat inherent to rivalry (Berendt and Uhrich, 2016).

The current study offered results that extend current understanding regarding the mechanisms of team identification and perceived fanship of rivals as each relates to fan behaviors. The predictive facet related to team identification between rival discussants in this investigation of recalled activation of fan behaviors was dichotomized among a sports fan's perception of their rival discussant's level of being a fan (i.e. fanship) and not their own level of being a fan. In other words, the more a rival discussant is perceived to be a fan, the more likely a sports fan is to engage in a rivalry fan behavior. Respondent team identification has been consistently measured in conjunction with fan behavior perceptions (Billings et al., 2017; Spinda, 2011; Wann and Branscombe, 1993, 1990), and consistently those measurements have highly correlated and been noted as antecedent. Those results were partly due to similar
Adding insult to rivalry 
measurements (for example, the BIRGing studies that additionally measured the SSIS scale), and partly due to capturing the uniplex respondent perceptions and not multiplex recalled behavior. The current study takes this research a step further by first removing the duplication of measures to protect against multicollinearity and then captures fan behaviors in this activated multiplex manner. Thus, findings indicate that team identification is indeed significant in relation to activated fan behaviors, but that significance rests upon the outward perceived fanship of others with whom a fan activates those behaviors. This is a significant finding, given that all prior research points to a fan's identification with his or her favorite team as the activating predictor to engage in fan behaviors. This study, however, instead suggests our focus on the importance of team identification should extend from the fan to include the fans' social ecosystem. Billings et al. (2017) had concluded part of a fan's identification is to have a named rival. The current study builds on that research and adds that a fan's perception of their rival discussants' level of fanship triggers fan behavior as a superiority component of image management strategy (Tajfel and Turner, 1979; Wann, 2006).

The second research question explored which GORFing and schadenfreude components trigger derogatory communication between rival discussants. This question was posited under the operationalized assumption that blasting is a communicated rivalry fan behavior (Cialdini and Richardson, 1980; Spinda, 2011). The GORFing components included socialization, in-group bias, sense of satisfaction and indirect competition. Schadenfreude components included joy, pride and personally insulting a rival discussant.

GORFing. Disidentification as a component of rivalry was evident in this study, given that only 313 rival discussants were named among 1,029 respondents. Socialization was captured as the rival-fan relationship since this research examined rival discussants. The sports consumption relational exchanges in that relationship would test the socialization aspect of GORFing. The relational exchanges measured as socialization components (watch, attend, talk about sports together) were all insignificant, as would be expected between rival discussants. This result is expected because respondents would hypothetically work toward disassociating with their named rival discussants. Havard (2014) wrote, "the dyadic nature of rivalry" causes the fan to display "disidentification from a rival team and its fan base" (p. 247).

Schadenfreude. The likelihood to express joy, pride and personally insult rival discussants were consistently significant predictors of out-group derogation. Joy and pride were significant predictors when respondents blasted rival discussants following a loss to the respondent's favorite team, but neither joy nor pride were significant predictors when a rival discussant's team loses to any team, which theoretically dichotomizes schadenfreude from the indirect component of GORFing. Pride was communicated by respondents when blasting followed a win by their favorite team, but respondents did not perceive pride as a significant component when being blasted by their rival discussants.

Personally insulting a rival discussant, however, was significant in all four models and was the most significant of all the variables in each of the models, and especially so in the indirect competition model. This supports prior research that indicates NFL fans harbor animosity against their perceived rivals (Cobbs et al., 2017; Havard, 2014).

\section{Managerial implications}

From a managerial standpoint, the results of this research help sport marketers better understand not only how the fans of their teams react to wins and losses but how these results impact how they communicate their feelings with each other. Given the increased prominence of digital marketing approaches and social media in the marketing plans of sport organizations, the findings assist those tasked with communicating team-related messages via social media. For example, given that that the respondents' level of team identification was not a significant predictor in the activation of outward blasting behaviors, perhaps social 
media managers may be able to utilize wins against rivals as a potential strategy in engaging and encouraging online discourse among fans who may not be as highly identified.

While rivalry has become an important marketing tactic by sport organizations, sponsoring brands have also begun to implement advertising campaigns focusing on rivals and how rivalry impacts their behaviors in competition. As an example, Gatorade recently debuted a campaign featuring the Houston Texans' J.J. Watt entitled "Make your rival your fuel." The campaign, which featured university rivalries such as the University of Texas/ University of Oklahoma and University of North Carolina/Duke University, as well as professional rivalries such as Barcelona/Real Madrid, Boston Red Sox/New York Yankees, and Green Bay Packers/Chicago Bears, encouraged the use of rivalry as a motivating factor in training for athletes. From the perspective of the fan, perhaps a similar campaign could be extended to the concept of schadenfreude, and recommend its implementation in encouraging playful discourse among rival fans. In turn, while Gatorade suggests that rivalry helps to make one a better athlete, perhaps the utilization of schadenfreude in fan communication could help cement one's reputation as a more dedicated and supportive fan.

For example, "when marketers understand how GORFing operates within the consumer sector, they can plan and implement measures to utilize the sense of satisfaction to engage better with consumers" (Havard et al., 2018, p. 5). Sports fans thrive on feeling joy at their rivals' adversity and this research revealed that fans discuss game outcomes with one-third of their already-established online and offline social network members. Therefore, one way in which sports marketers can engage with consumers is by giving them something to say-or wear - so that fans might highlight that pride and with joy. For example, research has noted that identification is "a strong predictor for cognition, positive attitude formations, and reported purchase intentions" (Devlin and Billings, 2018, p. 68). Thus, offering sport consumers products that suggest or express derogatory statements toward rival teams will likely sell to these fans who have something to prove to those in their discussion networks. Moreover, rivals have a storied past (Converse and Reinhard, 2016), so specifically including past game statistics or other related stories could offer sports consumers something to "talk trash" about with their rival discussants, thus enabling the much sought-after feeling of the superiority aspect of a sports fan's social identity (Billings et al., 2017; Converse and Reinhard, 2016; Tajfel and Turner, 1979; Wann, 2006).

\section{Limitation, future research and conclusion}

Limitations exist in this research. For example, the exchanges captured between rival discussants are the surveyed respondents' perceptions of those exchanges, whether they are online or in-person communication exchanges, based upon their personal recall and experiences and does not account for the rival discussant's perspective. Future research should investigate the implications of fanship perceptions between rivals and examine fan perceptions and behavior by collecting data in this multiplex manner to better capture social interactions. Moreover, this research suggests that schadenfreude should take a more prominent role in future investigations regarding sport, given that schadenfreude could have reach into greater financial, societal or moral implications regarding sport.

Schadenfreude should become a significant construct within the body of fan behavior literature and deserves further recognition and study in the sport marketing literature. Should schadenfreude and GORFing be one in the same, as Billings et al. (2017) operationalized? This research suggests that varying components of schadenfreude are activated in differing scenarios, so perhaps the dichotomization of affective and behavioral elements of fan behaviors should be examined further. For instance, both the expression of joy and personally insulting rival discussants were expressed in blasting outwardly and in being blasted. Insulting was added as a schadenfreude measurement, given that Cikara et al. 
(2011) found a likelihood for sport fans to personally insult a rival fan; even though neither Havard (2014) nor Billings et al. (2017) included personal insults in their respective measurements. However, here rival discussants were found to engage in such an extreme derogatory exchange, even above and beyond "talking trash." The combination of rival discussants' fanship being perceived higher than one's own level of team identification, and insulting rival discussants in addition to expressing joy and pride, are all reflective of the comparative basis of social identity theory. Thus, they can be categorized as reactionary attempts at image management (Cialdini and Richardson, 1980), expressed in response to identity threat of oneself and their favorite team (Wann, 2006).

In closing, we suggest future dichotomization among fan perceptions and fan behavior. Some fan behaviors are indeed behavioral, like BIRGing or blasting, but others are rooted in psychosocial antecedents rather than actualized behavior. Our results suggest, for example, that schadenfreude consists of affective antecedents to communicated fan behavior and GORFing serves as a categorization for fan behavior intensity (e.g. direct vs. indirect). As such, this research revealed how fan behavior can be better captured and subsequently measured by examining both the antecedent perceptions, and more importantly, the actualized activation of behaviors in the same study.

\section{References}

Ashforth, B.E. and Mael, F. (1989), "Social identity theory and the organization", Academy of Management Review, Vol. 14 No. 1, pp. 20-39, doi: 10.5465/AMR.1989.4278999.

Berendt, Johannes. and Sebastian, U. (2016), "Enemies with benefits: the dual role of rivalry in shaping sports fans' identity”, European Sport Management Quarterly, Vol. 16 No. 5, pp. 613-634.

Bernache-Assollant, I., Lacassagne, M.F. and Braddock, J.H. (2007), "Basking in reflected glory and blasting: differences in identity-management strategies between two groups of highly identified soccer fans", Journal of Language and Social Psychology, Vol. 26 No. 4, pp. 381-388, doi: 10.1177/ $0261927 X 07306981$.

Billings, A.C., Qiao, F., Brown, K.A. and Devlin, M. (2017), "Fandom, rival successes and failures, and the introduction of glory out of reflected failure measurements", in Billings, A.C. and Brown, K.A. (Eds), Evolution of the Modern Sport Fan: Communicative Approaches, Lexington Books, London, p. 65.

Branscombe, N.R. and Wann, D.L. (1994), "Collective self-esteem consequences of outgroup derogation when a valued social identity is on trial", European Journal of Social Psychology, Vol. 24 No. 6, pp. 641-657, doi: 10.1002/ejsp.2420240603.

Brown-Devlin, N., Devlin, M.B. and Vaughan, P.W. (2017), "Why fans act that way: using individual personality to predict BIRGing and CORFing behaviors", Communication and Sport, doi: 10. 1177/2167479517725011.

Bush, A.N., Walker, A.M. and Perry, B.L. (2017), “The family plan': characteristics of ties described as both 'friend' and 'family' in personal networks", Network Science, Vol. 5 No. 1, pp. 92-107, doi: 10.1017/nws.2017.2.

Campbell, R.M., Aiken, D. and Kent, A. (2004), "Beyond BIRGing and CORFing: continuing the exploration of fan behavior", Sport Marketing Quarterly, Vol. 13 No. 3, pp. 151-157.

Cialdini, R.B. and Richardson, K.D. (1980), "Two indirect tactics of image management: basking and blasting", Journal of Personality and Social Psychology, Vol. 39 No. 3, pp. 406-415, doi: 10.1037/ 0022-3514.39.3.406.

Cialdini, R.B., Borden, R.J., Thorne, A., Walker, M.R., Freeman, S. and Sloan, L.R. (1976), "Basking in reflected glory: three (football) field studies", Journal of Personality and Social Psychology, Vol. 34 No. 3, pp. 366-375, doi; 10.1037/0022-3514.34.3.366. 
Cikara, M. and Fiske, S.T. (2012), "Stereotypes and Schadenfreude: affective and physiological markers of pleasure at outgroup misfortunes", Social Psychological and Personality Science, Vol. 3 No. 1, pp. 63-71, doi: 10.1177/1948550611409245.

Cikara, M., Botvinick, M.M. and Fiske, S.T. (2011), "Us versus them: social identity shapes neural responses to intergroup competition and harm", Psychological Science, Vol. 22 No. 3, pp. 306-313, doi: $10.1177 / 0956797610397667$.

Cobbs, J., Sparks, B.D. and Tyler, B.D. (2017), "Comparing rivalry effects across professional sports: national football league fans exhibit most animosity", Sport Marketing Quarterly, Vol. 26 No. 4, pp. 235-246, available at: https://papers.ssrn.com/sol3/papers.cfm?abstract_id=3158547.

Converse, B.A. and Reinhard, D.A. (2016), "On rivalry and goal pursuit: shared competitive history, legacy concerns, and strategy selection”, Journal of Personality and Social Psychology, Vol. 110 No. 2, p. 191, doi: 10.1037/pspa0000038.

Devlin, M. and Billings, A.C. (2018), "Examining confirmation biases: implications of sponsor congruency", International Journal of Sports Marketing and Sponsorship, Vol. 19 No. 1, pp. 5873, doi: 10.1108/IJSMS-10-2016-0078.

Dietz-Uhler, B. and Murrell, A. (1999), "Examining fan reactions to game outcomes: a longitudinal study of social identity", Journal of Sport Behavior, Vol. 22 No. 1, pp. 15-27.

End, C.M., Dietz-Uhler, B., Harrick, E.A. and Jacquemotte, L. (2002), "Identifying with winners: a reexamination of sport fans' tendency to BIRG, Journal of Applied Social Psychology, Vol. 32 No. 5, pp. 1017-1030, doi: 10.1111/j.1559-1816.2002.tb00253.x.

Funk, D.C. and James, J. (2001), "The psychological continuum model: a conceptual framework for understanding an individual's psychological connection to sport", Sport Management Review, Vol. 4 No. 2, pp. 119-150, doi: 10.1016/S1441-3523(01)70072-1.

Gantz, W., Wang, Z., Paul, B. and Potter, R.F. (2006), "Sport versus all comers: comparing TV sport fans with fans of other programming genres", Journal of Broadcasting and Electronic Media, Vol. 50 No. 1, pp. 95-118, doi: 10.1207/s15506878jobem5001_6.

Harker, J. (2018), “Crisis Perceptions, Fan Behaviors, and Egocentric Discussion Networks: An Investigation into the Impervious Nature of NFL Crises", available from ProQuest Dissertations Publishing, available at: https://search.proquest.com/openview/b8f6d3 0545a90ee15a5032c6cbb58706/1?pqorigsite1/4gscholar\&cbl1/418750\&diss1/4y.

Havard, C.T. and Dalakas, V. (2017), "Understanding the marketing implications of sport rivalry: what we know and where we are headed", Sport Marketing Quarterly, Vol. 26 No. 4, pp. 199-203.

Havard, C.T. and Hutchinson, M. (2017), "Investigating rivalry in professional sport", International Journal of Sport Management, Vol. 18, pp. 422-440.

Havard, C.T., Gray, D.P., Gould, J., Sharp, L.A. and Schaffer, J.J. (2013), "Development and validation of the sport rivalry fan perceptions scale”, Journal of Sport Behavior, Vol. 36 No. 1, pp. 45-65, doi: 10.1037/t42563-000.

Havard, C.T. (2014), "Glory out of reflected failure: the examination of how rivalry affects sport fans", Sport Management Review, Vol. 17 No. 3, pp. 243-253, doi: 10.1016/j.smr.2013.09.002.

Heider, F. (1958), The Psychology of Interpersonal Relation, Wiley, New York.

Hirt, E.R. and Clarkson, J.J. (2011), "The psychology of fandom: understanding the etiology, motives, and implications of fanship", Consumer Behavior Knowledge for Effective Sport and Event Marketing, pp. 59-85.

Jensen, J.A., Turner, B.A., Delia, E., James, J., McEvoy, C., Seifried, C., Ross, S. and Walsh, P. (2016), "Forty years of BIRGing: new perspectives on Cialdini's seminal studies", Journal of Sport Management, Vol. 30 No. 2, pp. 149-161, doi: 10.1123/jsm.2015-0340.

Jensen, J.A., Greenwell, T.C., Coleman, C., Stitsinger, M. and Andrew, D. (2018), "From BIRFing to BIRGing: a 10-year study of the psychology of Cubs fans", Sport Marketing Quarterly, Vol. 27 No. 4, pp. 236-249. 
Kruse, N.W. (1977), "Motivational factors in non-denial apologia", Central States Speech Journal, Vol. 28 No. 1, pp. 13-23, doi: 10.1080/10510977709367915.

Kruse, N.W. (1981), “Apologia in team sport”, Quarterly Journal of Speech, Vol. 67 No. 3, pp. 270-283, doi: $10.1080 / 00335638109383572$.

Leach, C.W. and Spears, R. (2009), "Dejection at in-group defeat and schadenfreude toward second-and third-party out-groups", Emotion, Vol. 9 No. 5, pp. 659-665, doi: 10.1037/a0016815.

Leach, C.W., Spears, R., Branscombe, N.R. and Doosje, B. (2003), "Malicious pleasure: schadenfreude at the suffering of another group", Journal of Personality and Social Psychology, Vol. 84 No. 5, pp. 932-943, doi: 10.1037/0022-3514.84.5.932.

Leach, C.W., Spears, R. and Manstead, A.S. (2015), "Parsing (malicious) pleasures: schadenfreude and gloating at others' adversity", Frontiers in Psychology, Vol. 6, p. 201, doi: 10.3389/fpsyg. 2015.00201.

Mael, F. and Ashforth, B.E. (1992), "Alumni and their alma mater: a partial test of the reformulated model of institutional identification", Journal of Institutional Behavior, Vol. 13 No. 2, pp. 103-123, doi: 10.1002/job.4030130202.

Marsden, P.V. (1987), "Core discussion networks of Americans”, American Sociological Review, Vol. 52 No. 1, pp. 122-131, doi: 10.2307/2095397.

Perry, B.L. and Pescosolido, B.A. (2010), "Functional specificity in discussion networks: the influence of general and problem-specific networks on health outcomes", Social Networks, Vol. 32 No. 4, pp. 345-357, doi: 10.1016/j.socnet.2010.06.005.

Perry, B.L. and Pescosolido, B.A. (2015), "Social network activation: the role of health discussion partners in recovery from mental illness, Social Science and Medicine, Vol. 125 No. 1, pp. 116-128, doi: 10.1016/j.socscimed.2013.12.033.

PhenX Toolkit (1991), "Protocol: social networks", available at: https:/www.phenxtoolkit.org.

Rees, T., Haslam, S.A., Coffee, P. and Lavallee, D. (2015), "A social identity approach to sport psychology: principles, practice, and prospects”, Sports Medicine, Vol. 45 No. 8, pp. 1083-1096, doi: 10.1007/s40279-015-0345-4.

Reysen, S. and Branscombe, N.R. (2010), "Fanship and fandom: comparisons between sport and nonsport fans", Journal of Sport Behavior, Vol. 33 No. 2, pp. 176-193.

Sigelman, L. (1986), "Basking in reflected glory revisited: an attempt at replication, Social Psychology Quarterly, Vol. 49 No. 1, pp. 90-92, doi: 10.2307/2786860.

Spinda, J.S. (2011), "The development of basking in reflected glory (BIRGing) and cutting off reflected failure (CORFing) measures", Journal of Sport Behavior, Vol. 34 No. 4, pp. 392-420.

Tajfel, H. and Turner, J.C. (1979), "An integrative theory of intergroup conflict”, Social Psychology of Intergroup Relations, Vol. 33 No. 47, p. 74.

Tajfel, H. and Turner, J.C. (1986), "The social identity theory of inter group behavior", in Worchel, S. and Austin, W.G. (Eds), Psychology of Intergroup Relations, Nelson, Chicago.

Tajfel, H. (1982), "Social psychology of intergroup relations", Annual Review of Psychology, Vol. 33 No. 1, pp. 1-39, doi: 10.1146/annurev.ps.33.020182.000245.

Tyler, B.D. and Cobbs, J. (2015), "Rival conceptions of rivalry: why some competitions mean more than others", European Sport Management Quarterly, Vol. 15 No. 2, pp. 227-248, doi: 10.1080/ 16184742.2015.1010558.

Tyler, B.D. and Cobbs, J. (2017), "All rivals are not equal: clarifying misrepresentations and discerning three core properties of rivalry, Journal of Sport Management, Vol. 31 No. 1, pp. 1-14, doi: 10. 1123/jsm.2015-0371.

Tyler, B.D., Cobbs, J., Nichols, B.S. and Dalakas, V. (2019), "Schadenfreude, rivalry antecedents, and the role of perceived sincerity in sponsorship of sport rivalries, Journal of Business Research, doi: 10.1016/j.jbusres.2019.09.029. 
van der Vaart, W. and Glasner, T. (2011), "Personal landmarks as recall aids in survey interviews", Field Methods, Vol. 23 No. 1, pp. 37-56, doi: 10.1177/1525822X10384367.

Wann, D.L. and Branscombe, N.R. (1990), "Die-hard and fair-weather fans: effects of identification on BIRGing and CORFing tendencies", Journal of Sport and Social Issues, Vol. 14 No. 2, pp. 103-117, doi: 10.1177/019372359001400203.

Wann, D.L. and Branscombe, N.R. (1993), "Sport fans: measuring degree of identification with their team", International Journal of Sport Psychology, Vol. 24, pp. 1-17.

Wann, D.L. and Dolan, T.J. (1994), "Spectators' evaluations of rival and fellow fans", Psychological Record, Vol. 44 No. 3, p. 351, doi: 10.1007/BF03395919.

Wann, D.L., Melnick, M.J., Russell, G.W. and Pease, D.G. (2001), Sport Fans: The Psychology and Social Impact of Spectators, Routledge, New York, NY.

Wann, D.L. (2006), "Understanding the positive social psychological benefits of sport team identification: the team identification-social psychological health model", Group Dynamics: Theory, Research, and Practice, Vol. 10 No. 4, pp. 272-296, doi: 10.1037/1089-2699.10.4.272.

Weiner, B. (1986), An Attributional Theory of Motivation and Emotion, Springer-Verlag, New York, NY.

Weiner, B. (2008), "Reflections on the history of attribution theory and research: people, personalities, publications, problems", Social Psychology, Vol. 39 No. 3, pp. 151-156, doi: 10.1027/1864-9335.39. 3.151 .

\section{Corresponding author}

Jennifer L. Harker can be contacted at: jennifer.harker@mail.wvu.edu

For instructions on how to order reprints of this article, please visit our website:

www.emeraldgrouppublishing.com/licensing/reprints.htm

Or contact us for further details: permissions@emeraldinsight.com 